\title{
Convenient methods for preparing $\pi$-conjugated linkers as building blocks for modular chemistry
}

\author{
Jiří Kulhánek, Filip Bureš ${ }^{*}$ and Miroslav Ludwig
}

\section{Full Research Paper}

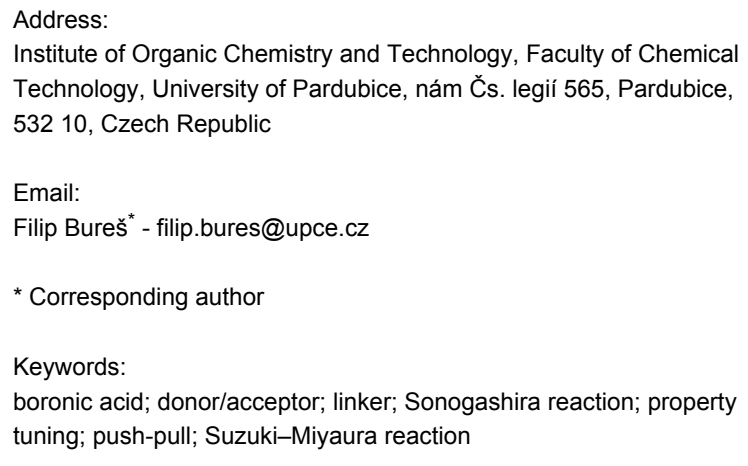

Beilstein Journal of Organic Chemistry 2009, 5, No. 11 doi:10.3762/bjoc.5.11

Received: 12 February 2009

Accepted: 07 April 2009

Published: 14 April 2009

Associate Editor: P. Skabara

(c) 2009 Kulhánek et al; licensee Beilstein-Institut. License and terms: see end of document.

\begin{abstract}
Simple, straightforward and optimized procedures for preparing extended $\pi$-conjugated linkers are described. Either unsubstituted or 4-donor substituted $\pi$-linkers bearing a styryl, biphenyl, phenylethenylphenyl, and phenylethynylphenyl $\pi$-conjugated backbone are functionalized with boronic pinacol esters as well as with terminal acetylene moieties allowing their further use as building blocks in Suzuki-Miyaura or Sonogashira coupling reactions.
\end{abstract}

\section{Introduction}

Development of new organic compounds with improved and advanced properties is one of the most important goals of modern material chemistry. Organic chemists steadily attempt to design and synthesize novel and well-defined organic pushpull systems with prospective applications as chromophores for nonlinear optics (NLO) [1-5], dyes [6], electronic and photonic devices [7,8], organic light-emitting diodes (OLED) [9] or functional polymers [10-13]. A typical push-pull chromophore consists of a polar A- $\pi$-D system with a planar $\pi$-system endcapped by a strong electron donor (D) and a strong electron acceptor (A). The $\pi$-conjugated system ensuring charge-transfer (CT) between the donor ( $\mathrm{D}=\mathrm{NR}_{2}$, OR groups etc.) and the acceptor ( $\mathrm{A}=\mathrm{NO}_{2}, \mathrm{CN}$ groups etc.) is most commonly comprised of double and triple bonds, aromatic and heteroaro- matic rings as well as their combinations [14-19]. A typical synthetic approach to CT chromophores involves either a stepwise formation of the target molecule $[19,20]$ or a separate preparation of the donor as well as the acceptor moieties and their final combination $[21,22]$. It is already well known that the HOMO/LUMO gap and polarizability of the push-pull systems with the given donors and acceptors can be finely tailored by the extension or shortening of the $\pi$-conjugated path between the donor and acceptor [19,21,23-25]. Thus, the latter modular synthetic approach seems to be more suitable for the property tuning described above. The final combination, $\mathrm{C}-\mathrm{C}$ bond formation, of the donor and acceptor chromophore moieties is usually accomplished by cross-coupling reactions, in particular by the Suzuki-Miyaura [26,27] or the Sonogashira [28] reac- 
tions. Consequently, the availability of the suitably substituted $\pi$-conjugated linkers of various lengths bearing boronic ester functionality or terminal acetylene is crucial for such a synthetic approach. Hence, we report here a convenient synthesis as well as characterization of either unsubstituted $(\mathrm{R}=\mathrm{H})$ or donor substituted $\left(\mathrm{R}=\mathrm{NMe}_{2}, \mathrm{OMe}\right) \pi$-conjugated linkers designed for the Suzuki-Miyaura and Sonogashira cross-couplings with a systematically varied and enlarged $\pi$-conjugated path (Figure $1)$.

Whereas the simplest linkers such as 4-substituted phenylboronic pinacol esters 1a-c [29] and ethynylbenzenes $\mathbf{2 a - c}$ [30] are well known and also commercially available, the proposed dioxaborolanes 3-6 feature styryl (series 3), biphenylyl (series 4), (E)-phenylethenylphenyl (series 5), and phenylethynylphenyl (series 6) linkers and $\mathrm{H}$ (series a), OMe (series b), and $\mathrm{NMe}_{2}$ (series c) groups as the substituent $\mathrm{R}$, respectively (Figure 1, Table 1). The terminal acetylenes $7 \mathbf{c}-\mathbf{9 c}$ possess only the strongest $\mathrm{NMe}_{2}$ donor and have an identical backbone to the one described above (Figure 1, Table 1).

\section{Results and Discussion}

\section{Synthesis of boronic pinacol esters 3-6}

Whilst two styryl dioxaborolanes $\mathbf{3 a - b}$ are known [31,32] and commercially available, the $N, N$-dimethylamino substituted derivative $3 \mathbf{c}$ needed to be synthesized. In order to achieve pure $(E)-3 c$, at first, a hydroboration of the commercially available terminal acetylene $\mathbf{2 c}$ with catecholborane was examined. Despite all attempts to optimize the reaction conditions, 3c could not be prepared this way and was not even detected in the crude reaction mixture. Thus the above hydroboration reported by Perner and co-workers [33] proved to be infeasible. However, in light of the report by Itami and Yoshida [34], we attempted the Mizoroki-Heck C-H arylation of 4-bromo- $N, N$ dimethylaniline with an equimolar amount of vinylboronate pinacol ester leading to the desired $\mathbf{3 c}$ in $73 \%$ yield (Scheme 1, Method A).

4-Substituted 4'-bromobiphenyl intermediates necessary for the preparation of $\mathbf{4 a - c}$ were synthesized by the Suzuki-Miyaura cross-coupling of 1-bromo-4-iodobenzene with the corresponding boronic acids/esters $\mathbf{1 a}-\mathbf{c}$ in the yields of 82,84 , and

\begin{tabular}{|c|c|c|c|}
\hline Entry & Product (R) & Method & Yield (\%) \\
\hline 1 & $3 c\left(\mathrm{NMe}_{2}\right)$ & $A$ & $73^{a}$ \\
\hline 2 & 4b (OMe) & $B$ & $81^{a}$ \\
\hline 3 & 4c $\left(\mathrm{NMe}_{2}\right)$ & $B$ & $83^{a}$ \\
\hline 4 & $5 \mathbf{a}(\mathrm{H})$ & $\mathrm{C}$ & $76^{b}$ \\
\hline 5 & 5b (OMe) & C & $69^{a}$ \\
\hline 6 & $5 c\left(\mathrm{NMe}_{2}\right)$ & $\mathrm{C}$ & $82^{a}$ \\
\hline 7 & $\mathbf{6 a}(\mathrm{H})$ & $\mathrm{D}$ & $78^{a}$ \\
\hline 8 & 6b (OMe) & $\mathrm{D}$ & $72^{a}$ \\
\hline 9 & $6 c\left(\mathrm{NMe}_{2}\right)$ & $\mathrm{D}$ & $91^{a}$ \\
\hline 10 & $10 / 7 c$ & $E$ & $98 / 92^{c}$ \\
\hline 11 & $11 / 8 c$ & $E$ & $97 / 91^{\mathrm{C}}$ \\
\hline 12 & $12 / 9 c$ & $E$ & $99 / 89^{c}$ \\
\hline
\end{tabular}

aYield of the final coupling step. ${ }^{b}$ Horner-Wadsworth-Emmons reaction. cYield of the Sonogashira cross-coupling (10-12) and final TMS-group removal to the terminal acetylenes $7 \mathrm{c}-9 \mathrm{c}$.

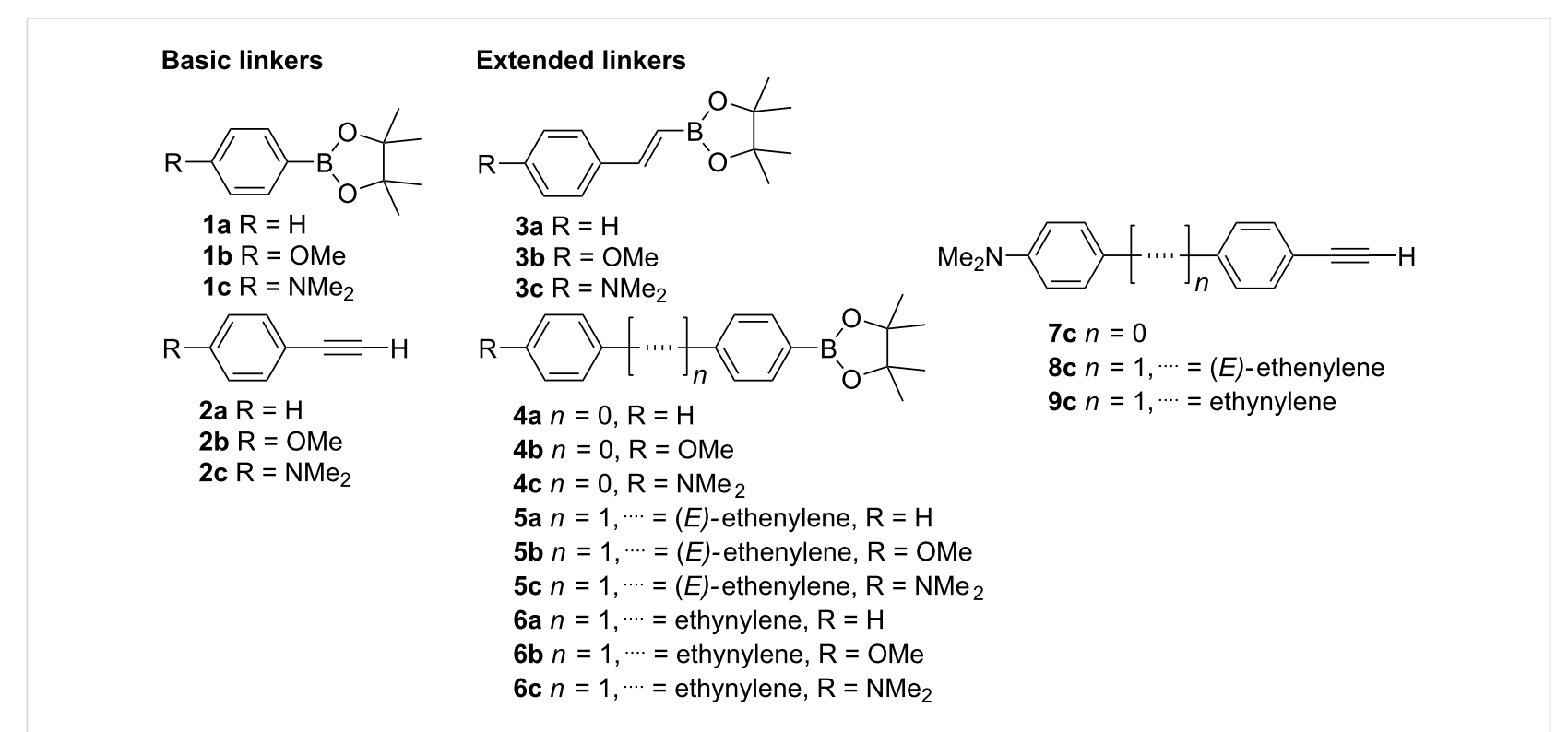

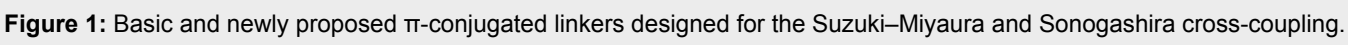




\section{Method A:}

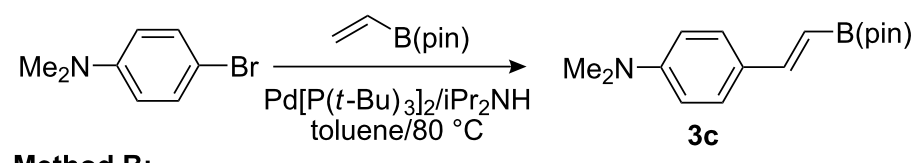

Method B:

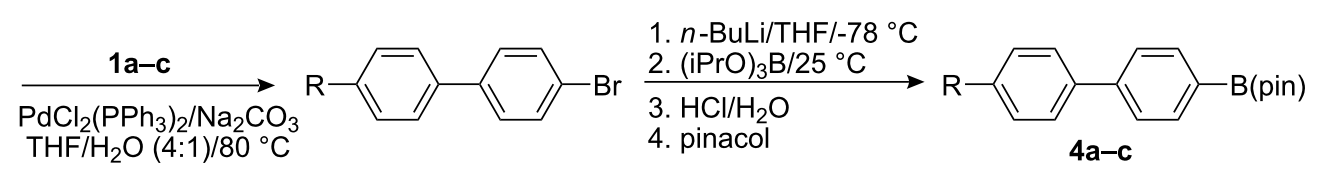

Method C:
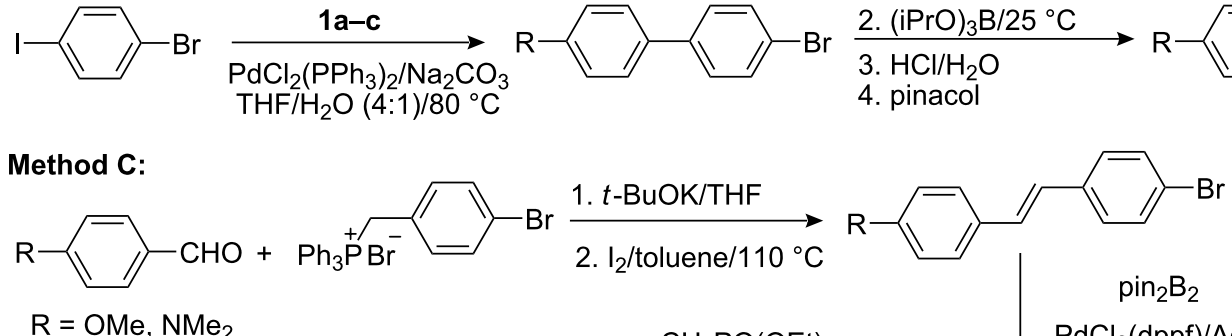

$\mathrm{R}=\mathrm{OMe}, \mathrm{NMe}_{2}$
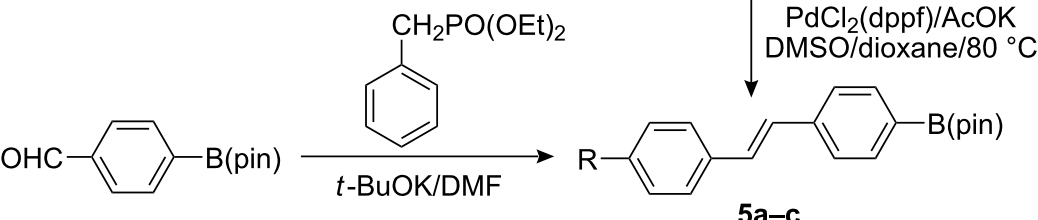

Method D:
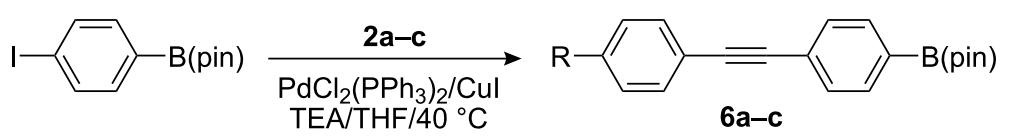

Scheme 1: Convenient synthetic methods leading to m-linkers 3-6.

$91 \%$, respectively. A routine procedure involving a lithiation and reaction with triisopropyl borate followed by esterification with pinacol afforded dioxaborolanes $\mathbf{4 b}-\mathbf{c}$ in the yields of 81 and $83 \%$ (Scheme 1, Method B). The biphenyl-4-boronic acid corresponding to $\mathbf{4 a}$ was also commercially available while $\mathbf{4 b}$ was reported as a side product [35] without full characterization.

Whereas 5a was easily accessible as a pure $(E)$-product from the pinacol ester of 4-formylphenylboronic acid and diethyl benzylphosphonate through the Horner-Wadsworth-Emmons reaction in $76 \%$ yield [36], methoxy and $N, N$-dimethylamino substituted $(E)$-4-bromostilbenes were synthesized from the corresponding benzaldehydes and 4-bromobenzyl(triphenyl)phosphonium bromide [37] by the Wittig reaction [37,38] in 37 and $54 \%$ yields, respectively. In contrast to the Horner-Wadsworth-Emmons reaction, this procedure afforded both $(E)$ - and $(Z)$-stilbenes that were isomerized by heating with traces of iodine in toluene to afford pure $(E)$-stilbenes [38]. However, compared to $\mathrm{N}, \mathrm{N}$-dimethylaminostilbene, the isomerization of 4-bromo-4'-methoxystilbene required twelve times the prolonged reaction time ( 4 vs. $48 \mathrm{~h}$ ) while the isomerisation of unsubstituted 4-bromostilbene did not take a place at all. Hence, 5a had to be prepared by the Horner-Wadsworth-Emmons reaction described above. These substituted 4-bromostilbenes could be most effectively converted to target pinacol esters $\mathbf{5 a}-\mathbf{c}$ via borylation (Scheme 1, Method C) utilizing bis(pinacolato)diboron $\left(\operatorname{pin}_{2} \mathrm{~B}_{2}\right)$ [39] in a mixed solvent system DMSO/dioxane ensuring good solubility. It should be noted here that $5 \mathbf{a}-\mathbf{c}$ were also accessible via the routine sequence showed for Method B. On the contrary, borylation of 4-bromobiphenyls with $\operatorname{pin}_{2} \mathrm{~B}_{2}$ (Method $\mathrm{C}$ ) yielded only traces of $4 \mathbf{a}-\mathbf{c}$.

Linear phenylethynylphenyl $\pi$-linkers $\mathbf{6 a - c}$ were gained by a Sonogashira cross-coupling between the pinacol ester of 4-iodophenylboronic acid [39] and terminal acetylenes 2a-c (Scheme 1, Method D) in 72-91\% yield. Table 1 (entries 1-9) summarizes the used synthetic methods and yields for the particular dioxaborolanes 3-6.

\section{Synthesis of terminal acetylenes 7-9}

Synthesis of $N, N$-dimethylamino substituted terminal acetylenes $7 \mathbf{c}-9 \mathbf{c}$ was accomplished by Sonogashira cross-coupling as shown on the Scheme 2 (Method E). The reaction utilizes the 4-bromo derivatives used as precursors for the construction of dioxaborolanes 4-6 and the product of the Sonogashira crosscoupling between $2 \mathbf{c}$ and 1,4-diiodobenzene (54\% yield). Since the Sonogashira reaction between bromo derivatives and trimethylsilylacetylene proved to be sluggish and low yielding 


\section{Method E:}

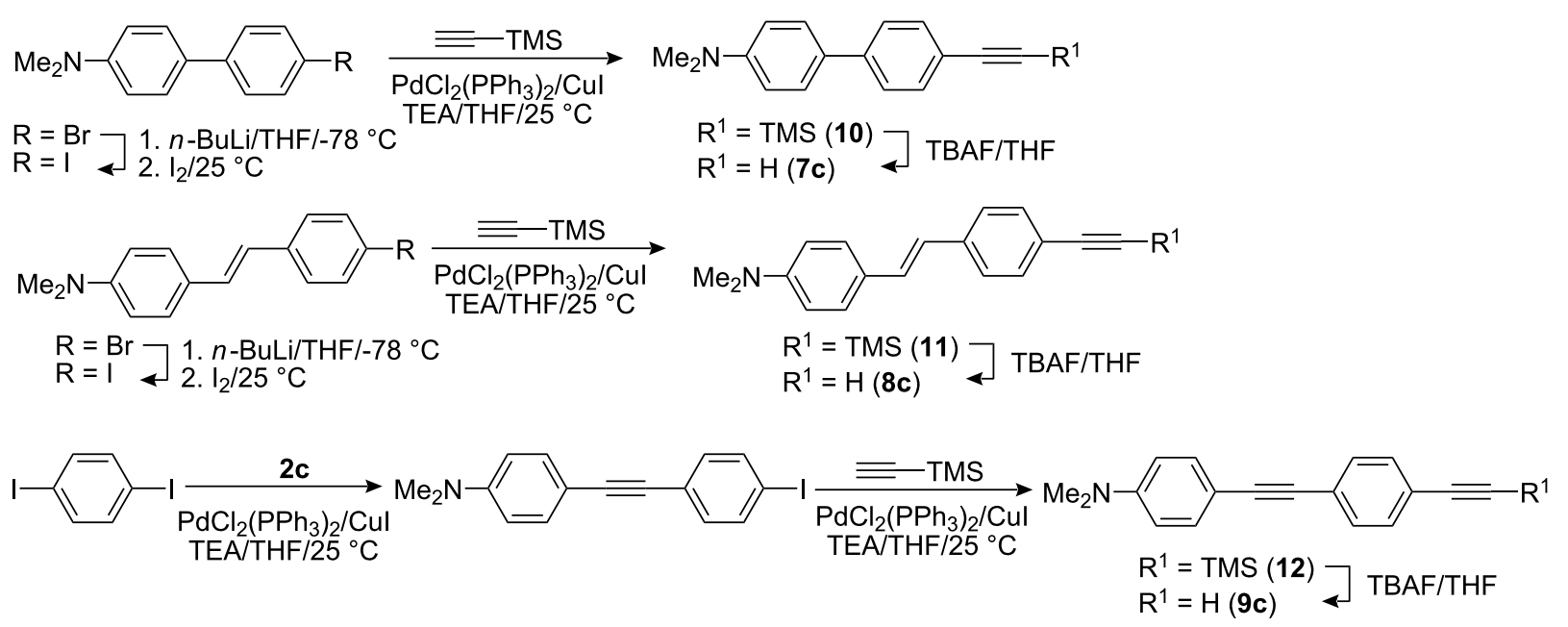

Scheme 2: Sonogashira cross-coupling leading to m-linkers $7 c-9 c$.

(even with a large excess of acetylene and elevated temperature), the bromo derivatives were converted to the corresponding iodo derivatives by lithiation and quenched with iodine (see Supporting Information File 1). Thus the Sonogashira reaction on iodo derivatives smoothly furnished TMSprotected acetylenes 10-12 in high yields and reaction times of about 30 min while the subsequent TMS group removal using TBAF (tetrabutylammonium fluoride) afforded desired $\pi$-linkers 7c-9c (Scheme 2, Table 1, entries 10-12). A similar synthesis of the linear $\pi$-linker $9 \mathrm{c}$ has already been reported [40]. Moreover, unprotected terminal acetylenes $\mathbf{7 c - 9} \mathbf{c}$ showed good stability with no signs of decomposition upon standing over several months which facilitate their storage and use.

\section{Conclusion}

It has been shown that extended, donor-substituted $\pi$-conjugated linkers can be easily prepared using commercially available precursors under either conventional or modern synthetic conditions. The reaction procedures reported here refer to the optimized procedures for each class of derivatives. Overall 12 extended $\pi$-linkers have been easily synthesized ( 8 of them are new compounds) utilizing procedures such as a lithiation/reaction with triisopropyl borate/esterification with pinacol, Mizoroki-Heck coupling with vinylboronate pinacol ester, borylation with bis(pinacolato)diboron or Sonogashira coupling. Further application of the above boronic esters as well as terminal acetylenes for the construction of imidazole-based $\mathrm{D}-\pi$-A systems by Suzuki-Miyaura and Sonogashira reaction is currently in progress in our laboratory.

\section{Supporting Information}

\section{Supporting Information File 1}

Experimental procedures and characterization of compounds.

[http://beilstein-journals.org/bjoc/content/supplementary/ 1860-5397-5-11-S1.doc]

\section{Supporting Information File 2}

${ }^{1} \mathrm{H}$ NMR spectra as well as GC/MS records for target compounds 3-9.

[http://beilstein-journals.org/bjoc/content/supplementary/ 1860-5397-5-11-S2.pdf]

\section{Acknowledgments}

This research was supported by the Ministry of Education, Youth and Sport of the Czech Republic (MSM 0021627501 and LA09041).

\section{References}

1. Albota, M.; Beljonne, D.; Brédas, J.-L.; Ehrlich, J. E.; Fu, J.-Y.; Heikal, A. A.; Hess, S. E.; Kogej, T.; Levin, M. D.; Marder, S. R.; McCord-Maughon, D.; Perry, J. W.; Röckel, H.; Rumi, M.; Subramaniam, G.; Webb, W. W.; Wu, X.-L.; Xu, C. Science 1998, 281, 1653-1656. doi:10.1126/science.281.5383.1653

2. Marder, S. R. Chem. Commun. 2006, 131-134. doi:10.1039/b512646k

3. Kivala, M.; Boudon, C.; Gisselbrecht, J.-P.; Seiler, P.; Gross, M.; Diederich, F. Angew. Chem., Int. Ed. 2007, 46, 6357-6360. doi:10.1002/anie.200701733 
4. Bureš, F.; Schweizer, W. B.; Boudon, C.; Gisselbrecht, J.-P.; Gross, M.; Diederich, F. Eur. J. Org. Chem. 2008, 994-1004. doi:10.1002/ejoc.200700970

5. Juríček, M.; Kasák, P.; Stach, M.; Putala, M. Tetrahedron Lett. 2007, 48, 8869-8873. doi:10.1016/j.tetlet.2007.10.044

6. Li, Z.; Qin, A.; Lam, J. W. Y.; Dong, Y.; Dong, Y.; Ye, C.; Williams, I. D.; Tang, B. Z. Macromolecules 2006, 39, 1436-1442. doi:10.1021/ma051924f

7. Cumpston, B. H.; Ananthavel, S. P.; Barlow, S.; Dyer, D. L.; Ehrlich, J. E.; Erskine, L. L.; Heikal, A. A.; Kuebler, S. M.; Lee, I.-Y. S.; McCord-Maughon, D.; Qin, J.; Röckel, H.; Rumi, M.; Wu, X.-L.; Marder, S. R.; Perry, J. W. Nature 1999, 398, 51-54. doi:10.1038/17989

8. Moonen, N. N. P.; Gist, R.; Boudon, C.; Gisselbrecht, J.-P.; Seiler, P.; Kawai, T.; Kishioka, A.; Gross, M.; Irie, M.; Diederich, F. Org. Biomol. Chem. 2003, 1, 2032-2034. doi:10.1039/b303879c

9. Haldi, A.; Kimyonok, A.; Domercq, B.; Hayden, L. E.; Jones, S. C.; Marder, S. R.; Weck, M.; Kippelen, B. Adv. Funct. Mater. 2008, 18, 3056-3062. doi:10.1002/adfm.200800446

10. Kraft, A.; Grimsdale, A. C.; Holmes, A. B. Angew. Chem., Int. Ed. 1998 37, 402-428.

doi:10.1002/(SICI)1521-3773(19980302)37:4<402::AID-ANIE402>3.0. CO;2-9

11. Ma, H.; Liu, S.; Luo, J.; Suresh, S.; Liu, L.; Kang, S. H.; Haller, M.; Sassa, T.; Dalton, L. R.; Jen, A. K.-Y. Adv. Funct. Mater. 2002, 12, 565-574. doi:10.1002/1616-3028(20020916)12:9<565::AID-ADFM565>3.0.CO;28

12. Kivala, M.; Diederich, F. Acc. Chem. Res. 2009, 42, 235-248. doi:10.1021/ar8001238

13. Do, J. Y.; Ju, J. J. Macromol. Chem. Phys. 2005, 206, 1326-1331. doi:10.1002/macp.200400547

14. Pahadi, N. K.; Camacho, D. H.; Nakamura, I.; Yamamoto, Y. J. Org. Chem. 2006, 71, 1152-1155. doi:10.1021/jo052262v

15. Hennrich, G.; Asselberghs, I.; Clays, K.; Persoons, A. J. Org. Chem. 2004, 69, 5077-5081. doi:10.1021/jo049279i

16. Wang, J.; Lu, M.; Pan, Y.; Peng, Z. J. Org. Chem. 2002, 67, 7781-7786. doi:10.1021/jo026186x

17. Kivala, M.; Stanoeva, T.; Michinobu, T.; Frank, B.; Gescheidt, G.; Diederich, F. Chem.-Eur. J. 2008, 14, 7638-7647. doi:10.1002/chem.200800716

18. Spitler, E. L.; Shirtcliff, L. D.; Haley, M. H. J. Org. Chem. 2007, 72, 86-96. doi:10.1021/jo061712w

19. Patel, A.; Bureš, F.; Ludwig, M.; Kulhánek, J.; Pytela, O.; Růžička, A. Heterocycles 2009, 78, 999-1013. doi:10.3987/COM-08-11609

20. Batista, R. M. F.; Costa, S. P. G.; Belsley, M.; Lodeiro, C.; Raposo, M. M. M. Tetrahedron 2008, 64, 9230-9238. doi:10.1016/j.tet.2008.07.043

21. Bureš, F.; Schweizer, W. B.; May, J. C.; Boudon, C.; Gisselbrecht, J.-P.; Gross, M.; Biaggio, I.; Diederich, F. Chem.-Eur. J. 2007, 13, 5378-5387. doi:10.1002/chem.200601735

22. Andersson, A. S.; Kerndrup, L.; Madsen, A. Ø.; Kilså, K.; Nielsen, M. B.; La Porta, P. R.; Biaggio, I. J. Org. Chem. 2009, 74, 375-382. doi:10.1021/jo802190q

23. May, J. C.; Biaggio, I.; Bureš, F.; Diederich, F. Appl. Phys. Lett. 2007, 90, No. 251106. doi:10.1063/1.2750396

24. Wan, J.-H.; Feng, J.-C.; Wen, G.-A.; Wei, W.; Fan, Q.-L.; Wang, C.-M.; Wang, H.-Y.; Zhu, R.; Yuan, X.-D.; Huang, C.-H.; Huang, W. J. Org. Chem. 2006, 71, 2565-2571. doi:10.1021/jo0521596

25. Bureš, F.; Pytela, O.; Diederich, F. J. Phys. Org. Chem. 2009, 22 , 155-162. doi:10.1002/poc.1443
26. Miyaura, N.; Suzuki, A. Chem. Rev. 1995, 95, 2457-2483. doi:10.1021/cr00039a007

27. Kotha, S.; Lahiri, K.; Kashinath, D. Tetrahedron 2002, 58, 9633-9695. doi:10.1016/S0040-4020(02)01188-2

28. Chinchilla, R.; Nájera, C. Chem. Rev. 2007, 107, 874-922. doi:10.1021/cr050992x

29. Murata, M.; Watanabe, S.; Masuda, Y. J. Org. Chem. 1997, 62, 6458-6459. doi:10.1021/jo970963p

30. Elangovan, A.; Wang, Y.-H.; Ho, T.-I. Org. Lett. 2003, 5, 1841-1844. doi:10.1021/ol034320+

31. Mkhalid, I. A. I.; Coapes, R. B.; Edes, S. N.; Coventry, D. N.; Souza, F. E. S.; Thomas, R. L.; Hall, J. J.; Bi, S.-W.; Lin, Z.; Marder, T. B. Dalton Trans. 2008, 1055-1064. doi:10.1039/b715584k

32. Murata, M.; Kawakita, K.; Asana, T.; Watanabe, S.; Masuda, Y. Bull. Chem. Soc. Jpn. 2002, 75, 825-829. doi:10.1246/bcsj.75.825

33. Perner, R. J.; Lee, C.-H.; Jiang, M.; Gu, Y.-G.; DiDomenico, S.; Bayburt, E. K.; Alexander, K. M.; Kohlhaas, K. L.; Jarvis, M. F.; Kowaluk, E. L.; Bhagwat, S. S. Bioorg. Med. Chem. Lett. 2005, 15, 2803-2807. doi:10.1016/j.bmcl.2005.03.098

34. Itami, K.; Tonogaki, K.; Ohashi, Y.; Yoshida, J.-i. Org. Lett. 2004, 6, 4093-4096. doi:10.1021/ol048217b

35. Chaumeil, H.; Le Drian, C.; Defoin, A. Synthesis 2002, 757-760. doi:10.1055/s-2002-25773

36. Oehlke, A.; Auer, A. A.; Jahre, I.; Walfort, B.; Rüffer, T.; Zoufalá, P.; Lang, H.; Spange, S. J. Org. Chem. 2007, 72, 4328-4339. doi:10.1021/j0070084v

37. Ren, Y.; Yu, X.-Q.; Zhang, D.-J.; Wang, D.; Zhang, M.-L.; Xu, G.-B.; Zhao, X.; Tian, Y.-P.; Shao, Z.-S.; Jiang, M.-H. J. Mater. Chem. 2002, 12, 3431-3437. doi:10.1039/b206578a

38. Liu, Z.-q.; Fang, Q.; Wang, D.; Cao, D.-x.; Xue, G.; Yu, W.-t.; Lei, H. Chem.-Eur. J. 2003, 9, 5074-5084. doi:10.1002/chem.200304833

39. Perttu, E. K.; Arnold, M.; lovine, P. M. Tetrahedron Lett. 2005, 46, 8753-8756. doi:10.1016/j.tetlet.2005.10.033

40. Rodriguez, J. G.; Esquivias, J.; Lafuente, A.; Rubio, L. Tetrahedron 2006, 62, 3112-3122. doi:10.1016/j.tet.2006.01.032

\section{License and Terms}

This is an Open Access article under the terms of the Creative Commons Attribution License (http://creativecommons.org/licenses/by/2.0), which permits unrestricted use, distribution, and reproduction in any medium, provided the original work is properly cited.

The license is subject to the Beilstein Journal of Organic Chemistry terms and conditions:

(http://www.beilstein-journals.org/bjoc)

The definitive version of this article is the electronic one which can be found at: $\underline{\text { doi:10.3762/bjoc.5.11 }}$ 